\title{
CEREBELLAR CONTRIBUTION TO ABSENCE EPILEPSY
}

\author{
Leonid S. Godlevsky ${ }^{0000-0003-0935-8255}$, Oleh R. Pinyazhko ${ }^{0000-0002-0961-5656}$, \\ and Olesya B. Poshyvak
}

${ }^{l}$ Godlevsky Leonid, PhD, professor, ${ }^{2,3}$ Pinyazhko Oleh, PhD, doc.hab., professor, ${ }^{2}$ Poshyvak Olesya, PhD, associate professor

${ }^{1}$ Department of Biophysics, Informatics and Medical Devices, Odesa National Medical University, Odesa,

${ }_{2}^{2}$ Pharmacology Department, Danylo Halytsky Lviv National Medical University, Lviv, Ukraine

${ }^{3}$ Department of Civilization Diseases and Regenerative Medicine, WSIiZ, Rzeszow, Poland

Address all correspondence to:

Godlevsky Leonid,

Department of Biophysics,

Informatics and Medical Devices,

Odesa National Medical University,

2, Valikhovsky Lane, Odesa - 65082, Ukraine

Email: godlevskyleonid@yahoo.com

Tel.: +38048-7178916

\section{Running title: Cerebellum and absence epilepsy}

\begin{abstract}
The new aggregate data analyses revealed the earlier missing role played by the cerebellum long-term electrical stimulation in the absence epilepsy. Neurophysiologic data gained by authors favor that cerebellar serial deep brain stimulation (DBS) $(100 \mathrm{~Hz})$ causes the transformation of penicillin-induced cortical focal discharges into prolonged 3,5-3,75 sec oscillations resembling spikewave discharges (SWD) in cats. Such SWDs were not organized in the form of bursts and persisted continuously after stimulation. Therefore the appearance of prolonged periods of SWD is regarded as a tonic cerebellar influence upon
\end{abstract}


pacemaker of SWD and might be caused by the long-lasting DBS-induced increase of GABA-ergic extrasynaptic inhibition in forebrain networks. At the same time, cerebellar DBS high-frequency $(100 \mathrm{~Hz})$ suppressed bursts of SWD observed during the phase of stimulation. Different types of cerebellar DBS upon epileptic activity emphasized the absence seizure facilitation discussed with the reviewed data on optogenetic stimulation, neuronal activity of cerebellar structures, and functional magnetic resonance imaging data.

Key words: absence epilepsy, spike-wave discharges, cerebellum, deep brain stimulation.

\begin{abstract}
Abbreviations: AS - absence seizures; BOLD - blood-oxygen-level-dependent (response); CAE - childhood absence epilepsy; CTC - cortico-thalamo-cortical (network); DBS - deep brain stimulation; EEG - electroencephalogram; eGABAAR - extrasynaptic gamma aminobutyric acid type A receptors; ES electrical stimulation; GHB - $\gamma$-hydroxybutyric acid (butyrolactone); fMRI functional magnetic resonance imaging; GABA $\gamma$-aminobutyric acid; PC Purkinje cells; PPC- primary positive component; RT- reticular (thalamic) nucleus; SWD - spike-wave discharges; TMS - transcranial magnetic stimulation. [18F]FDG-PET - fludeoxyglucose (18F) - positron emission tomography.
\end{abstract}




\section{INTRODUCTION}

Childhood absence epilepsy (CAE) represents a benign form of generalized epilepsy, which comprises $10-15 \%$ of all childhood epilepsies [1, 2, 3]. Both experimental and clinical absence seizures (AS) represent minimal visible clinical symptoms and typical and profound EEG deterioration [4-8].

Main pathogenetic peculiarities of spike-wave discharges (SWD) as a biomarker of AS confined to hyperexcitation within the cortico-thalamo-cortical (CTC) network [6-9]. Intensively developed investigations of genetic forms of absence seizures performed during the last decades [10-14]. Calcium channel deteriorations may underlay such hyperactive state of neurons within the CTC networks due to an $\alpha(1 \mathrm{~A})$ voltage-sensitive calcium channel gene mutation - as established in tottering $(\operatorname{tg})$ and $\operatorname{tg}(\mathrm{la})$ mice $[14,15,16,17]$.

Recent data proved that a pathological enhancement of GABAergic signaling within a thalamocortical network is necessary and sufficient for nonconvulsive AS development [18-25]. The overwhelming inhibitory GABA-ergic effect is in charge of absence SWD promotion $[18,19,26]$. It might be assumed that increased activation of extrasynaptic GABAA receptors and augmented tonic GABAA inhibition in thalamocortical neurons are in charge of such effect [20].

Continuously developed absence seizures in rats induced via gamma-butyrolactone (GHB) $(200 \mathrm{mg} / \mathrm{kg}$, i.p.) administration is characterized by a lower frequency of discharges $(2,64-3,59 \mathrm{~Hz})$, which are not organized as bursts [24, 27]. The enhanced GABAergic inhibition serves as a basic conception of AS manifestations, and compounds which intensified it recognized as proabsence ones [25]. The reticular thalamic nucleus (RT) 's leading role in the GABA-ergic suppression of specific thalamic nuclei was strengthened last time [28]. Such data were in line 
with the two-phase effects of vigabatrin upon SWD [29] and with the suppression of SWD caused by DBS of RT [30].

Despite relatively good pharmacological control of CAE manifestations, resistance to treatment is actual [31-34]. Searching for alternative therapy of not-responsive AS targets for DBS proved promising [35]. Among others, thalamic structures are the first line of such targets $[30,35,36]$, while the cerebellum is almost beyond the scope of interest.

Meanwhile, considering the statement on GABA role in AS, the question arises if the cerebellum could be a source of additional strengthening of GABA-ergic mechanisms provoking AS?

To answer such a question means observing the evolution of epileptic activity induced as a result of GABA inhibition disturbance caused by penicillin antagonist of CABAA receptors under conditions of cerebellar ES. Penicillin induced activity is recognized as closely resembling SWD, and systemic administration of epileptogen to feline cats is a hallmark of such resemblance [37]. Nevertheless, foci induced via application of relatively low dosage of penicillin solution upon brain cortex start their activity from purely negative spikes and demonstrate step by step development of particular discharge (spike) component such as primary slow-wave, positive component (PPC) following spike [38]. Such a "minor" characteristic of epileptic discharges might be informative for antiseizure action of antiepileptic drugs [38, 39]. We were interested in two phenomena, which are underlying with GABAergic mechanisms. Namely, GABAmediated inhibition contributes to the profound postsynaptic inhibitory potential of substantial length in penicillin-induced foci, which underlay slow-wave genesis [20-22, 26, 37]. The genesis of PPC reflects local inhibitory ("surround inhibition") [40-42] barrier activity, which does not permit to expand epileptic activity along with the neural tissue. 
Hence, our investigation aimed to observe the specificity evolution of interictal penicillin-induced cortical focal activity, emphasizing slow-wave characteristics, and spikes PPC under paleocerebellar electrical stimulation (ES).

\section{MATERIAL AND METHODS}

The experiments performed on 15 male cats, weighing 2,5-3,5 $\mathrm{kg}$ under acute experimental conditions. Procedures involving animals and their care were conducted according to University guidelines that comply with international laws and policies [European Community Council Directive 86/609, OJ L 358, I, December 12, 1987; National Institute of Health Guide for Care and Use of Laboratory Animals, US National Research Council, 1996].

All animals underwent tracheostomy and skull trepanation performed under ether anesthesia. Points of pressure in a stereotaxic frame and all soft tissue dissection zones were infiltrated with $0,5 \%$ of novocaine solution, and this procedure repeated every 2,0 h. Tubocurarine ("Orion," Finlandia, 0,2 mg/kg, i.v.) was injected, and after that, the cats were artificially ventilated. Stimulative nichrome bipolar electrodes (outer diameter 0,12 $\mathrm{mm}$, interelectrode distance 0,2 $\mathrm{mm}$ ) were inserted to the paleocerebellum (declive, pyramis) under visual control and fixed to the skull with quick-drying dental cement.

The dura mater was dissected 2,0-2,5 $\mathrm{h}$ from the moment of the cessation of ether anesthesia, and filter paper $(2,0 \mathrm{x} 2,0 \mathrm{~mm})$ was soaked with ex tempore prepared sodium benzylpenicillin solution $(16,000 \mathrm{IU} / \mathrm{ml})$ applied to the posterior sigmoidal gyrus. The indifferent electrode was then placed in nasal bones. Monopolar EEG registration performed using electroencephalograph 4- EEG-3 type (FSU). Electrical stimulations (ES) of the cerebellum were done with an electrostimulator ESU-1 (FSU) (100- $300 \mathrm{~Hz}, 0,25 \mathrm{~ms}, 150-250 \mu \mathrm{A}$, duration of trial- 3-7 s). The 
interval between ES was not less than three minutes. Only histologically controlled locations of electrodes were included in observation. Control cats were falsestimulated [43].

\section{RESULTS}

Fifteen to twenty min after the moment of application of the epileptogen upon the cat's cortex (posterior sigmoidal gyrus), single spikes with an amplitude of 1,5-2,2 $\mathrm{mV}$ and the frequency of generated discharges was 30 to 50 per min (Fig 1, A).
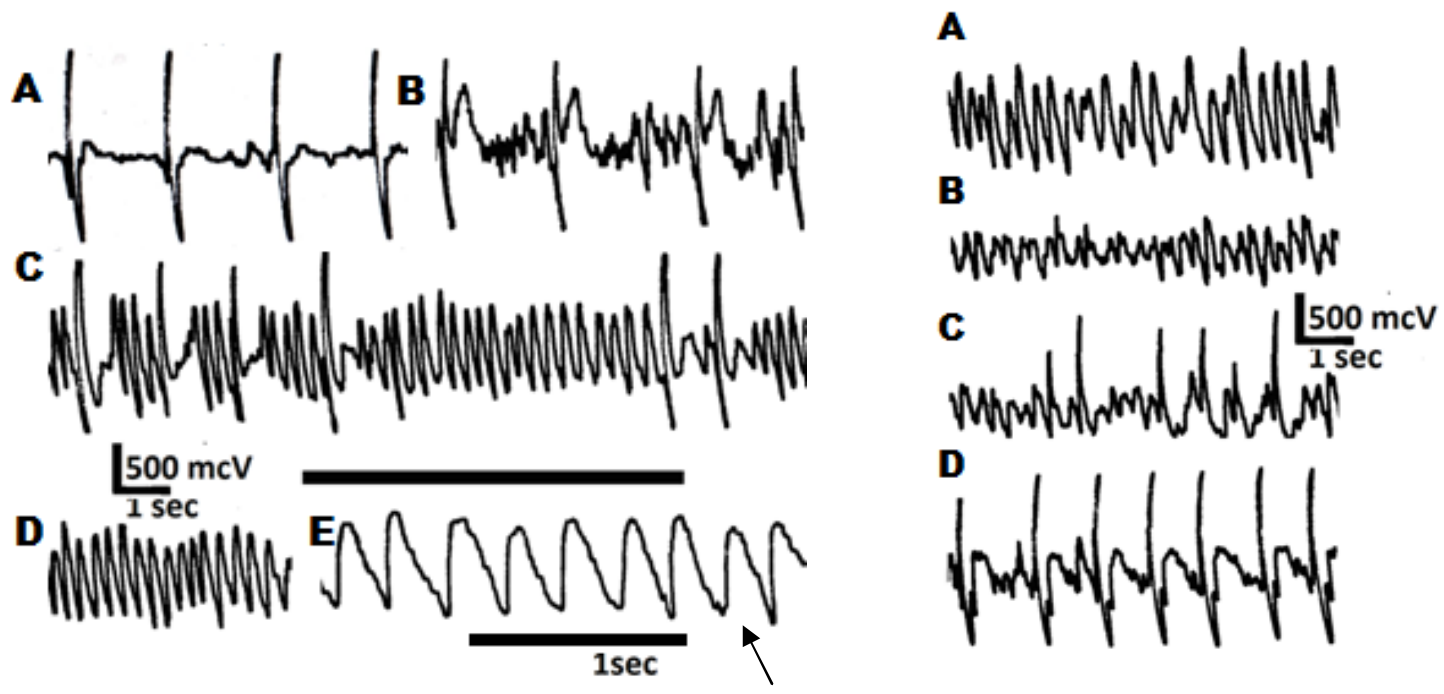

Fig.1 Effects of paleocerebellar ES upon penicillin-induced foci in brain cortex of myorelaxed and artificially ventilated cats A- 17,5 min after the moment of application of penicillin sodium salt $(16,000 \mathrm{IU} / \mathrm{ml})$ to the posterior sigmoid gyrus;

B-1,0 min after the cessation of 2-d ES and 5,5 min after A;

C-5th ES; D-, E- 1,0 min after the moment of 7th ES;

With an arrow, a small amplitude spike preceding a sharp wave marked.

Parameters of ES: $100 \mathrm{~Hz}, 0,25 \mathrm{~ms}, 250 \mathrm{mcA}$ (period of ES marked with a solid line at C).
Fig. 2 Effect of penicillin application in the zone with sharp spindle-like waves generation. A- 1,5 min from the moment of 8-th ES of paleocerebellum; B- 0,5 min, C- 2,5 min, and D- 5,5 min from the moment of the new application of benzylpenicillin $\quad(16,000$ $\mathrm{IU} / \mathrm{min}$ ).

(Adopted from [43]) 
Not regular and small PPC was registered at this period in control observations with false stimulations (as an example, look at fragment A, which demonstrates the period before ES start). More regular PPC with amplitude than $25 \%$ of the spike's total magnitude followed with slow wave appeared in the next 15,0 - 20,0 min in the control group. Meanwhile, the development of pronounced (up to $50 \%$ of the total magnitude of discharge) PPC of discharges followed with pronounced - up to 0,6 $\mathrm{mV}$ slow wave was induced in 1-3 ES (Fig. 1, B). This time, the discharge amplitude diminished to $1,3-1,8 \mathrm{mV}$, while the frequency of generation of discharges reduced to 15 - 45 per min. During the next 2-4 ESs, the suppression of spikes along with the appearance of slightly distorted sinusoidal waves $(3,5-$ $3,75 / \mathrm{sec}$ ) with an amplitude of 0,45-0,80 $\mathrm{mV}$ was registered (Fig 1, C). Consequent 2- 4 ES were enough to suppress all spiking activity. This effect was observed in 5 out of 7 experiments, and in all of them, spikes were substituted by relatively regular $(3,5-3,75 / \mathrm{sec})$ sinusoidal waveforms with a constant amplitude of 0,6 to 0,9 $\mathrm{mV}$ (Fig. 1, D, E). Not regularly, small amplitude spikes preceding wave were identified (look at E, the arrow pointed). It should stress that any SWD appearance was seen in control observation - false- stimulated cats with spontaneous declining focal activity.

New local application of penicillin $(16,000 \mathrm{IU} / \mathrm{ml})$ in the zone in which sinusoidal waves were present (Fig. 2, A) caused an initial decrease of their amplitude (Fig. 2, B) with the appearance of spikes in 1,0-3,0 min (Fig. 2, C). In the next 1,0-4,5 min, spikes' amplitude reached their maximal value (Fig. 2, D). Remarkably the PPC was absent in newly appeared discharges.

\section{DISCUSSION}

Hence, delivered results revealed the precipitation of not-in burst organized prolonged slow-wave activity with the frequency of $3,5-3,75 \mathrm{~Hz}$ in the zone of 
cortical penicillin-induced foci. Such activity is close to such one characteristic for absence SWD and induced via paleocerebellum ES.

As far as cortical administration of GABAA antagonists (penicillin) precipitated seizure activity with SW pattern $[44,45]$, the spontaneous occurrence of SWD was expected in the course of the natural decline of penicillin-induced foci activity. Such type of evolution did not take place in our observations but provoked with paleocerebellar ES. Obtained results correspond with the data on the precipitation of SWD $(3 / \mathrm{sec})$ in the rat brain cortex on the focal penicillin-induced foci model caused by paleocerebellar ES [47]. They correspond also with the theory on the leading cortical role in SWD generation $[9,46]$ and with the general conception on the role of GABA-ergic mechanisms in SWD precipitation.

Gained data permitted to state the next properties of described regular slow waves:

-waves rows are restricted to the zone of primary penicillin application and did not impact intact cortical zones;

-waves shape is asymmetrical with a sharp increase and slow decline of amplitude;

-suppression of slow waves caused by additional penicillin application - the fact in favor of their genesis via activation of CABA-dependent mechanisms of their appearance. Vice versa, the activation of local inhibition caused by cerebellar ES is also supported by the induction of pronounced PPC as far as its development reflects the state of local surround inhibition [40-42]. Precipitation of pronounced PPC was an immediate result of first-second stimulations.

Hence, it might be supposed that influences coming to the forebrain from stimulated paleocerebellum can precipitate EEG signs of AS in the cortical GABA-A mechanism zone disturbed with local penicillin application. This effect of $\mathrm{ES}$ is promoted by the increase of GABA-ergic inhibition in target neuronal chains as far as investigated components of seizure discharged (slow wave, PPC) 
reflect the heightened state of GABA inhibition and developed in parallel with the suppression of spike discharges $[43,47,48]$.

The involvement of GABA strengthened inhibition in observed effects of transformation of epileptic activity is supported with clinical magnetic resonance spectroscopy data revealing the heightening of GABA-ergic mechanisms in the brain caused by cerebellar transcranial magnetic stimulation (TMS) [49, 50]. The authors established that cerebellar TMS followed by an average increase of EEG synchronization in the theta-bandwidth, accompanied by the rise in regional GABA level in the prefrontal cortex [50].

Existing literature data coming from different methodical approaches to the clarifying cerebellar role in AS are in line with the gained data:

\subsection{Tonic onic and phasic effects of cerebellar ES}

The prolonged poststimulative character of SWD provocation is in favor of the tonic nature of AS facilitation, which might realize via extrasynaptic $\delta$-containing GABAA receptors [51] located both in the thalamus [52] and in the brain cortex $[53,54]$. It should stress that extrasynaptic tonic inhibition is necessary to induce AS. Thus, knockdown of eGABAAR by genetic methods prevented precipitation of AS both in the GHB model and spontaneous AS in GAERs rats [19]. GABA elaborated in cerebrospinal fluid in the course of high-frequency $(200 \mathrm{~Hz}) \mathrm{ES}$ of the cerebellum $[55,56]$ might also contribute to eGABAAR activation.

Another mechanism on such stimulation realized via the strengthening of GABA synthesis from glutamate elaborated from glutamatergic cerebellar efferents and accumulated in thalamic targets in the course of serial cerebellar ES has been assumed by Gornati SV and Hoebeek FE [see 57]. 
Opposite to tonic, phasic influences upon the CTC network are realized transsynaptically [58]. Hence, the disruption of the CTC network via prolonged depolarization of thalamic neurons and dysfacilitation of epileptogenesis, as a result, is recognized as the most probable antiseizure role played by cerebellar nuclei in SWD suppression [59]. Pharmacological (gabazine) local stimulation of cerebellar nuclei neuronal activity followed with SWD suppression favors the proposed conception [60].

Different effects of phasic and tonic effects of cerebellar ES upon SWD are in correspondence with suppressive action of intrathalamic administration of glutamate receptors agonists upon SWD, while similar administration of GABAergic compounds (gamma-vinil-GABA, tiagabin) stimulate SWD generation in rats with genetic forms of AS [61, 62].

\subsection{Imaging of absence seizure network}

It is challenging to apply positron emission tomography (PET) to investigate ictal phenomena and their interpretation [63]. That is why the case of absence status epilepticus is of particular interest in clarifying its pathogenesis with [18F]FDGPET method [64]. The authors concluded that thalamus activation, hypometabolism in frontal, parietal, and posterior cingulate cortices, and hypermetabolism in the cerebellum favor the maintenance of absence status (3-4 $\mathrm{Hz}$ rhythmic delta waves in EEG). Earlier, [65] delivered similar data based on [18F]FDG-PET in a patient with absence status. Namely, the authors pointed to bilateral thalamic hypermetabolism and frontal cortex hypometabolism. BOLD data on GSWD activity in patients with juvenile myoclonic epilepsy revealed the net cerebellum involvement with the negative relationships between the thalamus, cerebellum, frontal and sensorimotor-related areas [66-68]. 
Using EEG/fMRI, the source of generalized SWDs determined in patients who suffered from resistant idiopathic generalized epilepsies [69]. The authors analyzed 36 AS and revealed that peak blood-oxygen-level-dependent (BOLD) response was reached maximally in six seconds from the AS EEG onset with a simultaneous time-schedule for the temporal lobe. The stable peak of BOLD response in the cerebellum registered one sec after the thalamus's peak favors that ictal AS induce disturbances encompassing the cerebellum. Following the classical statement, seizures arise from the cerebral cortex, spreading to other structures, including the cerebellum [70]. Nevertheless, cerebellar structures' primary role in seizures generation is also suspected [71] and disclosed on pentylenetetrazol-modeled seizures in Zebrafish [72].

\subsection{Impulse activity of cerebellar cells in seizure suppression}

PCs are activated during the occurrence of SWD, as well. High voltage spindles, recorded epidurally from the rat sensorimotor neocortex, correlated with single or multiple unit activity in the cerebellar cortex and deep cerebellar nuclei [73]. Later on, [74] reported that slow synchronized oscillations in the neocortex drive slow oscillations in the cerebellar cortex. Specific changes of extracellular spike trains of cerebellar nuclei of Cacnala tg mice, another genetic absence model, precipitated in the course of SWD appearance, favor cerebellum involvement [75].

Up to $26 \%$ PC demonstrated an increase of complex spike activity and rhythmicity during generalized SWDs in homozygous tottering mice [76]. Those effects are better pronounced in the cerebellar cortex's lateral parts, which receive inferior olive inputs. Interestingly, the bilateral inferior olive lesion was produced by systemic administration of the neurotoxin 3acetylpyridine, followed by a proconvulsant state-specific for strychnine-induced seizures myoclonus [77]. 
New data coming from the optogenetic experimental approach must favor increased impulse activity. Either PC [78] or nuclei cells [60, 79] resulted in the suppression manifestations of temporal lobe epilepsy induced with intrahippocampal kainic acid administration.

That is why cerebellar cells' increased impulse activity induced in SWD development assumes that backward cerebellar efferent influences aim to seize and suppress seizure discharges. However, in the case of absence electrogenesis, such a situation is different from the temporal epilepsy model, and backward cerebellar influences could maintain absences manifestations.

\section{CONCLUSIONS AND PERSPECTIVES}

Hence, the presented data favors the modulative and triggering role of the cerebellum in AS electrographic manifestations. The cerebellum's pro-absence seizure potential may at least partially contribute to cerebellar DBS's inconsistency in experimental conditions and patients with resistant epilepsy [36, 71, 80-82].

Some perspectives comprise parallelism between minor AS behavioral manifestations and functionality of the cerebellum extended beyond motor control. Thus, the lately established cerebellar role in cognition [83-85] corresponds to the well-known disruption of consciousness and disturbing informational processes in $\mathrm{WAG} / \mathrm{rij}$ rats $[5,6,86,87]$.

AS prevalently occurred at an early age (5 - 12 years), and manifestations lessened with the aging. A similar schedule of cerebellar neurons degeneration was observed in aging [88]. Such parallelism, together with discussed data on the functional state of cerebellum and precipitation AS manifestations, permits the assumption that cerebellar influences severely modulate the absence-prone CTC network. Such a belief is in line with the data [89], who described a default mode 
network in patients with AS, which extended beyond the CTC network and included striatum and reticular pons structures.

\section{ACKNOWLEDGMENTS}

The authors express their thankfulness to Professor Gilles van Luijtelaar and Professor Coenen A.M.L. for their valuable critical remarks and recommendations.

Authors contribution. LS created the conception and wrote the manuscript. POleh and POlesya analyzed the data, contributed to final design and edited the manuscript.

Conflict of interest. The authors declare no competing financial interests

Ethics approval: The work was approved by the Ethics Committee of Odesa National Medical University and conforms to the European Communities Council Directive 24 November 1986 (86/609/EEC; National Institute of Health Guide for Care and Use of Laboratory Animals, US National Research Council, 1996). 


\section{REFERENCES}

1.Panayiotopoulos CP, Obeid T, Waheed G. Differentiation of typical absence seizures in epileptic syndromes. A video EEG study of 224 seizures in 20 patients. Brain 1989;112: 1039-56. doi: 10.1093/brain/112.4.1039

2.Loiseau P, Duché B, Pédespan JM. Absence epilepsies. Epilepsia 1995; 36: 1182-6. doi: 10.1111/j.1528-1157.1995.tb01060.x

3.Kessler SK, McGinnis E. A practical guide to treatment of childhood absence epilepsy. Pediatr Drugs 2019;21: 15-24 doi:10.1007/s40272-019-00325-x

4.Van Luijtelaar EL, Coenen AM. Two types of electrocortical paroxysms in an inbred strain of rats. Neurosci Lett 1986; 70(3): 393-7. doi: 10.1016/03043940(86)90586-0

5.Van Luijtelaar ELJM, Van der Werf SJ, Vossen JMH, Coenen AML. Arousal, performance and absence seizures in rats. Electroencephalogr Clin Neurophysiol 1991; 79: 430-34. doi:10.1016/00134694(91)90208-L

6. Coenen AML, Drinkenburg WHIM, Inoue M, Van Luijtelaar ELJM. Genetic models of absence epilepsy, with emphasis on the WAG/Rij strain of rats. Epilepsy Res 1992; 2: 75-86. doi:10.1016/0920-1211(92)90029-S

7. Marescaux C, Vergnes M, Depaulis A. Genetic absence epilepsy in rats from Strasbourg-a review. J Neural Transm 1992; 35(Suppl.): 37-69. doi:10.1007/978-3-7091-9206-1_4

8. Danober L, Deransart C, Depaulis A, Vergnes M, Marescaux C. Pathophysiological mechanisms of genetic absence epilepsy in the rat. Prog Neurobiol 1998; 55(1): 27-57. doi:10.1016/s0301-0082(97)00091-9

9. Meeren HK, Pijn JP, Van Luijtelaar EL, Coenen AM, Lopes da Silva FH. Cortical focus drives widespread corticothalamic networks during spontaneous absence seizures in rats. $J$ Neurosci 2002; 22(4): 1480-95. doi:10.1523/JNEUROSCI.22-04-01480.2002 
10. Van Luijtelaar G, Zobeiri M. Progress and outlooks in a genetic absence epilepsy model (WAG/Rij). Curr Med Chem 2014; 21(6): 704-21. doi:10.2174/0929867320666121119152913

11. Russo E, Citraro R, Constanti A, Leo A, Lüttjohann A, van Luijtelaar G, De Sarro G. Upholding WAG/Rij rats as a model of absence epileptogenesis: Hidden mechanisms and new theory on seizure development. Neurosci Biobehav Rev 2016; 71: 388-408. doi:10.1016/j.neubiorev.2016.09.017

12. Van Luijtelaar G, Zobeiri M, Lüttjohann A, Depaulis A. Experimental treatment options in absence epilepsy. Curr Pharm 2017; 37: 5577-92. doi:10.2174/1381612823666171017170226

13. Russo E, Citraro R. Pharmacology of epileptogenesis and related comorbidities in the WAG/Rij rat model of genetic absence epilepsy. $J$ Neurosci Methods 2018; 310 (1): 54-62. doi: 10.1016/j.jneumeth.2018.05.020

14. Marks WN, Zander NK, Cain SM, Snutch TP, Howland JG. The T-type calcium channel antagonist, Z944, alters social behavior in Genetic Absence Epilepsy Rats from Strasbourg. Behav Brain Res 2019; 361: 54-64. doi:10.1016/j.bbr.2018.12.021

15. Fletcher CF, Lutz CM, O’Sullivan TN, Shaughnessy JD Jr, Hawkes R, Frankel N, Copeland NG, Jenkins NA. Absence epilepsy in tottering mutant mice is associated with calcium channel defects. Cell 1996; 87(4): 607-17. doi: 10.1016/s0092-8674(00)81381-1

16. Huguenard JR. Block of T-type $\mathrm{Ca}\left({ }^{2+}\right)$ channels is an important action of succinimide antiabsence drugs. Epilepsy Curr 2002; 2: 49-52. doi: 10.1046/j.15357597.2002.00019.x

17. Ebner TJ, Chen G. "Tottering mouse", in Handbook of the Cerebellum and Cerebellar Disorders, eds. M. Manto, J.D. Schmahmann, F. Rossi, D.L. Gruol, N. Koibuchi. Springer, Dordrecht, 2013. pp. 1521-1540

18. Cope DW, Di Giovanni G, Fyson SJ, Orbán G, Errington AC, Lorincz ML, Gould TM, Carter DA, Crunelli V. Enhanced tonic GABAA inhibition in typical absence epilepsy. Nat Med 2009; 12: 1392-98. doi:10.1038/nm.2058 
19. Wong M. Too much inhibition leads to excitation in absence epilepsy. Epilepsy Curr 2010; 10(5): 131-32. doi:10.1111/j.1535-7511.2010.01379x

20. Errington AC, Cope DW, Crunelli V. Augmentation of tonic GABAA inhibition in absence epilepsy: therapeutic value of inverse agonists at extrasynaptic GABAA receptors. Adv Pharm Sci 2011; 790590. doi: $10.1155 / 2011 / 790590$

21. Crunelli V, Copea DW, Terry JR. Transition to absence seizures and the role of GABAA receptors. Epilepsy Res 2011; 97: 283-9. doi:10.1016/j.eplepsyres.2011.07.011

22.Crunelli V, Leresche N, Cope DW. "GABA-A Receptor Function in Typical Absence Seizures," in Jasper's Basic Mechanisms of the Epilepsies [Internet], eds. J.L.Noebels, M. Avoli, M.A. Rogawski, R.W. Olsen, A.V. Delgado-Escueta (Bethesda (MD): National Center for Biotechnology Information (US) (2012), Available from: https://www.ncbi.nlm.nih.gov/books/NBK98213/

23. Leal A, Vieira JP, Lopes R, Nunes RG, Gonçalves SI, da Silva FL, Figueiredo P. Dynamics of epileptic activity in a peculiar case of childhood absence epilepsy and correlation with thalamic levels of GABA Epilepsy Behav Case Rep 2016; 5: 57-65. doi:10.1016/j.ebcr.2016.03.004

24. Santos VR, Kobayashi I, Hammack R, Danko G, Forcelli, PA. Impact of strain, sex, and estrous cycle on gamma butyrolactone-evoked absence seizures in rats. Epilepsy Res 2018; 147: 62-70. doi:10.1016/j.eplepsyres.2018.09.007

25.Crunelli V, Lorincz ML, McCafferty C, Lambert RC, Leresche N, Di Giovanni G, David F. Clinical and experimental insight into pathophysiology, comorbidity and therapy of absence seizures. Brain 2020; 21: doi:10.1093/brain/awaa072 
26. Coenen AM, Blezer EH, van Luijtelaar EL. Effects of the GABA-uptake inhibitor tiagabine on electroencephalogram, spike-wave discharges and behaviour of rats. Epilepsy Res 1995; 21(2): 89-94. doi:10.1016/0920-1211(95)00015-3

27. Arcaro J, Ma J, Chu L, Kuo M, Mirsattari SM, Stan Leung L. The hippocampus participates in a pharmacological rat model of absence seizures. Epilepsy Res 2016;120:79-90. doi:10.1016/j.eplepsyres.2015.12.007

28. Huguenard J. Current controversy: spikes, bursts, and synchrony in generalized absence epilepsy: unresolved questions regarding thalamocortical synchrony in absence epilepsy. Epilepsy Curr 2019; 19(2): 105-11. doi: $10.1177 / 1535759719835355$

29. Perescis MFJ, van Luitelaar G, van Rijn CM. Immediate versus late effects of vigabatrin on spike and wave discharges. Epilep Res 2020; 165: 106379. doi: 10.1016/j.eplepsyres.2020.106379

30. Wang Z, Wang Q. Eliminating absence seizures through the deep brain stimulation to thalamus reticular nucleus. Front Comput Neurosci 2017; 11: 22. doi: $10.3389 /$ fncom.2017.00022

31. Kwan P, Brodie MJ. Early identification of refractory epilepsy. N Engl J Med 2000; 342: 314-9. doi: 10.1056/NEJM200002033420503

32. Wirrell E, Camfield C, Camfield P, Dooley J. Prognostic significance of failure of the initial antiepileptic drug in children with absence epilepsy. Epilepsia 2001; 42: 760-3. doi:10.1046/j.1528-1157.2001.02401.x

33. Ollivier ML, Dubois MF, Krajinovic M, Cossette P, Carmant L. Risk factors for valproic acid resistance in childhood absence epilepsy. Seizure 2009; 18(10): 690-4. doi: 10.1016/j.seizure.2009.09.007

34. Vossler DG, Yilmaz U. Ezogabine treatment of childhood absence epilepsy. Epileptic Disord 2014; 16 (1): 121-4. doi:10.1684/epd.2014.0645

35. Huang L, van Luijtelaar G. Search for new targets of deep brain stimulation for epilepsy treatment. J Neurol Res and Therapy 2016; 1(2): 23-33. doi: 10.14302/issn.2470-5020.jnrt-15-800 
36. Zangiabadi N, Ladino LD, Sina F, Orozco-Hernández JP, Carter A, Téllez-Zenteno JF. Deep brain stimulation and drug-resistant epilepsy: a review of the literature. Front Neurol 2019; 10:601. doi:10.3389/fneur.2019.00601

37. Kostopoulos G, Avoli M, Gloor P. Participation of cortical recurrent inhibition in the genesis of spike and wave discharges in feline generalized epilepsy. Brain Res 1983; 267: 101-12. doi: 10.1016/0006-8993(83)91043-0

38. Lueders H, Bustamante L, Zablow L, Krinsky A, Goldensohn ES. Quantitative studies of spike foci induced by minimal concentrations of penicillin. Electroencephalogr Clin Neurophysiol 1980; 48(1): 80-9. doi: 10.1016/00134694(80)90046-2

39. Silfverhuth MJ, Kortelainen J, Ruohonen J, Suominen K, Niinimäki J, Sonkajärvi E, Kiviniemi V, Alahuhta S, Jäntti V, Tervonen O and Seppänen T. A characteristic time sequence of epileptic activity in EEG during dynamic penicillin-induced focal epilepsy-A preliminary study, Seizure: European Journal of Epilepsy 2011; 20:7: 513-19. doi: 10.1016/j.seizure.2011.03.006

40. Ebersole JS, Levine RA. Abnormal neuronal responses during evolution of a penicillin epileptic focus in cat visual cortex. Journal of Neurophysiology 1975; 38: 250-56. doi: 10.1152/jn.1975.38.2.250

41. de Curtis M, Avanzini G. Interictal spikes in focal epileptogenesis. Progress in Neurobiology. 2001; 63: 541-67. doi: 10.1016/s03010082(00)00026-5

42. Traub RD. Cellular mechanisms underlying the inhibitory surround of penicillin epileptogenic foci. Brain Res 1983; 261(2): 277-84. doi: 10.1016/00068993(83)90630-3

43. Godlevsky LS Stepanenko KI. Precipitation of absence epilepsy in the course of electrical stimulation of paleocerebellar cortex in cats with simple partial epilepsy model. Proceedings of V.N.Karazin Kharkiv National University 2003; 597(6): 20-26. Available at: https://periodicals/karazin.ua/medicine/article/ view/7291/6778 
44. Gloor P, Quesney LF, Zumstein H. Pathophysiology of generalized penicillin epilepsy in the cat: the role of cortical and subcortical structures. II. Topical application of penicillin to the cerebral cortex and subcortical structures. Electroencephalogr Clin Neurophysiol 1977; 43: 79-94. doi: 10.1016/003-4694(77)90198-5

45. Steriade M, Contreras D. Spike-wave complexes and fast components of cortically generated seizures. I. Role of neocortex and thalamus. J Neurophysiol 1998; 80(3): 1439-55. doi: 10.1152/jn.1998.80.3.1439

46. Meeren HK, van Luijtelaar EL, Lopes da Silva FH, Berdiev RK, Chepurnova NE, Chepurnov SA, Coenen AM. Kortikotalamicheskaia teoriia proiskhozhdeniia generalizovannykh pik-volnovykh razriadov [The corticothalamic theory for generalised spike-wave discharges]. Usp Fiziol Nauk 2004; 35(1): 3-19. Russian. PMID: 15027170

47. Godlevsky LS, Polyasny VA, Gilles van Luijtelaar, Coenen AML. Paleocerebellar electrical stimulation induces the reduction of seizures and the development of absence epilepsy in rats with penicillin-induced epilepsy. $J$ Exp Clin Medicine 2012; 29(1): 46-51. doi:10.5835/jecm.omu.29.01.012

48. Godlevsky L, Nenova O, Voropay M, Prybolovets M, Pervak M. Electrical stimulation of cerebellar vermis induces absence epilepsy-like EEG activity in penicillin treated cats. J Neurol Sci 2017; 381(Suppl.): 694. doi: 10.1016.j.jns.2017.08.1953

49. Fernandez L, Major BP, Teo WP, Byrne LK, Ennicott PG. Assessing cerebellar brain inhibition (CBI) via transcranial magnetic stimulation (TMS): A systematic review. Neurosci Biobehav Rev 2018; 86: 176-206. doi: 10.1016/j.neubiorev.2017.11.018

50. Du X, Rowland LM, Summerfelt A, Choa FS, Wittenberg GF, Wisner K, Wijtenburg A, Chiappelli J, Kochunov P, Hong LE. Cerebellar- stimulation evoked prefrontal electrical synchrony is modulated by GABA. Cerebellum 2018; 17(5): 550-63. doi:10.1007/s12311-018-0945-2 
51. Chuang SH, Reddy DS. Genetic and molecular regulation of extrasynaptic GABA-A receptors in the brain: therapeutic insights for epilepsy. $J$ Pharmacol Exp Ther 2018; 364 (2): 180-97. doi:10.1124/jpet.117.244673

52. Mesbah-Oskui L, Orser BA, Horner RL. Thalamic $\delta$-subunit containing GABAA receptors promote electrocortical signatures of deep non-REM sleep but do not mediate the effects of etomidate at the thalamus In Vivo. J Neurosci 2014; 34 (37): 12253-66. doi:10.1523/JNEUROSCI.0618-14.2014

53. Drasbek KR, Jensen K. THIP, a hypnotic and antinociceptive drug, enhances an extrasynaptic GABA-A receptor-mediated conductance in mouse neocortex. Cereb Cortex 2006; 16: 1134-1141. doi:10.1093/cercor/bhj055

54. Mortensen M, Patel B, Smart TG. GABA Potency at GABA-A receptors found in synaptic and extrasynaptic zones. Front Cell Neurosci 2011; 6: 1-12. doi:10.3389/fncel.2012.00001

55. Obata K, Takeda K. Release of $\gamma$-aminobutyric acid into the fourth ventricle induced by stimulation of the cat's cerebellum. J Neurochem 1969; 16: 1043-47. doi:10.1111/j.1471-4159.1969.tb05948.x

56. Obata K. Synaptic inhibition and $\gamma$-aminobutyric acid in the mammalian central nervous system. Proc Jpn Acad Ser B Phys Biol Sci 2013; 89(4): 139-56. doi: 10.2183/pjab.89.139

57. Miterko LN, Baker KB, Beckinghausen J, Bradnam LV, Cheng MY, Cooperrider J, DeLong MR, Gornati SV, Hallett M, Heck DH, et al. Consensus paper: experimental neurostimulation of the cerebellum. The Cerebellum 2019; 18(6): 1064-97. doi: 10.1007/s12311-019-01041-5

58. Bohne P, Schwarz MK, Herlitze S, Mark MD. A new projection from the deep cerebellar nuclei to the hippocampus via the ventrolateral and laterodorsal thalamus in mice. Front Neural Circuits 2019; 13: 51. doi:10.3389/fncir.2019.00051

59. Salt TE, Copeland CS. "Metabotropic glutamate receptor function in thalamocortical circuitry," in: $m G L U$ Receptors, eds. R.T. Ngomba, G. Di 
Giovanni, G. Battaglia, F. Nicoletti (Springer International Publishing, Cham) (2017), 149-59. doi:10.1007/978-3-319-56170-7_8

60. Kros L, Eelkman Rooda OHJ, Spanke JK, Alva P, Van Dongen MN, Karapatis A, Tolner EA, Strydis C, Davey N, Winkelman BHJ et al. Cerebellar output controls generalized spike-and-wave discharge occurrence. Ann Neurol 2015; 77(6): 1027-49. doi:10.1002/ana.24399

61. Liu Z., Vergnes M., Depaulis A., Marescaux C. Evidence for a critical role of GABAergic transmission within the thalamus in the genesis and control of absence seizures in the rat. Brain Res. 1991; 545 (1-2): 1-7. doi: 10.1016/00068993(91)91262-y

62. D’Amore V., von Randow C., Nicoletti F., Ngomba R.T., Gilles van Luijtelaar Anti $\square$ absence activity of mGlu1 and mGlu5 receptor enhancers and their interaction with a GABA reuptake inhibitor: Effect of local infusions in the somatosensory cortex and thalamus. Epilepsia 2015; 56(7): 1141-1151. doi: 10.1111/epi.13024

63. Schura S, Allenc V, Whitec A, Mirskyd D, Stenced N, O’Neille B, Handlere M, Dudleyb R, Laoprasertc P. Significance of FDG-PET hypermetabolism in children with intractable focal epilepsy. Pediatr Neurosurg 2018; 53: 153-62. doi:10.1159/000487088

64. Shimogori K, Doden T, Oguchi K, Hashimoto T. Thalamic and cerebellar hypermetabolism and cortical hypometabolism during absence status epilepticus. BMJ Case Reports 2017; 220139. doi:10.1136/bcr-2017-220139

65. Bilo L, Meo R, Leva MF, Vicidomini C, Salvatore M, Pappata S. Thalamic activation and cortical deactivation during typical absence status monitored using [18F]FDG-PET: A case report. Seizure 2010; 19(3): 198-201. doi:10.1016/j.seizure.2010.01.00

66. Moeller F, Maneshi M, Pittau F, Gholipour T, Bellec P, Dubeau F, Grova C, Gotman J. Functional connectivity in patients with idiopathic generalized epilepsy. Epilepsia 2011; 52(3): 515-22. doi:10.1111/j.1528-1167.2010.02938.x 
67. Moeller F, Muthuraman M, Stephani U, Deuschl G, Raethjen J, Siniatchkin M. Representation and propagation of epileptic activity in absences and generalized photoparoxysmal responses. Hum Brain Mapp 2013; 34: 1896-909. doi: 10.1002/hbm.22026

68. Qin Y, Jiang S, Zhang Q, Dong L, Jia X, He H, Yao Y, Yang H, Zhang $\mathrm{T}$, Luo $\mathrm{C}$, et al. OLD-fMRI activity informed by network variation of scalp EEG in juvenile myoclonic epilepsy. NeuroImage: Clinical 2019; 22: 101759. doi: 10.1016/j.nicl.2019.101759

69. Szaflarski JP, Di Francesco M, Hirschauer T, Banks C, Priverta MD, Gotman J, Holland SK. Cortical and subcortical contributions to absence seizure onset examined with EEG/fMRI. Epilepsy Behav 2010; 18(4): 404-13. doi:10.1016/j.yebeh.2010.05.009

70. Filip P, Bareš M, Brázdi M. Cerebellar dysfunction and ataxia in patients with epilepsy: Coincidence, consequence, or cause? Tremor and Other Hyperkinetic Mov 2016; 23(6): 376. doi:10.7916/D8KH0NBT

71. Streng ML, Krook-Magnuson E. The cerebellum and epilepsy. Epilepsy Behav 2020: 106909. doi: 10.1016/j.yebeh.2020.106909

72.Cozzolino O, Sicca F, Paoli E, Trovato F, Santorelli FM, Ratto GM, Marchese M. Evolution of epileptiform activity in Zebrafish by statistical-based integration of electrophysiology and 2-photon Ca2+ imaging. Cells 2020; 9: 769. doi:10.3390/cells9030769

73. Kandel A, Buzsáki G. Cerebellar neuronal activity correlates with spike and wave EEG patterns in the rat. Epilepsy Res 1993; 16: 1-9. doi:10.1016/ 09201211(93)90033-4

74. Roš H, Sachdev RNS, Yu Y, Šestan N, McCormick DA. Neocortical networks entrain neuronal circuits in cerebellar cortex. J Neurosci 2009; 29 (33): 10309-20. doi: 10.1523/JNEUROSCI.2327-09.2009

75. Alva P, Kros L, Maex R, De Zeeuw CI, Adams R, Davey N, Steuber V, Hoebeek FE. A potential role for the cerebellar nuclei in absence seizures. BMC Neurosci 2013; 14(Suppl. 1): 170. doi: 10.1186/1471-2202-14-S1-P170 
76. Kros L, Lindeman S, Eelkman Rooda OHJ, Murugesan P, Bina L, Bosman LWJ, De Zeeuw CI, Hoebeek FE. Synchronicity and rhythmicity of Purkinje cell firing during generalized spike-and-wave discharges in a natural mouse model of absence epilepsy. Front Cell Neurosci 2017; 11: 346. doi:10.3389/fncel.2017.00346

77. Anderson MC, Chung E, Van Woert MH. The effects of inferior olive lesion on strychnine seizure. Brain Res Bul 1990; 25: 599-603. doi: 10.1016/00142999(88)90514-6

78. Krook-Magnuson E, Szabo GG, Armstrong C, Oijala M, Soltesz I. Cerebellar directed optogenetic intervention inhibits spontaneous hippocampal seizures in a mouse model of temporal lobe epilepsy. eNeuro 2014; 1(1): e.2014. doi:10.1523/ENEURO.0005-14.2014

79. Streng ML, Krook-Magnuson E. Excitation, but not inhibition, of the fastigial nucleus provides powerful control over temporal lobe seizures. $J$ Physiol 2020; 598(1): 171-87. doi: 10.1113/JP278747

80. Godlevsky LS, Van Luijtelaar G, Coenen AML, Shandra AA. Causes and consequences of pathogenic processes in evolution: Implications from experimental epilepsy in animals. Med Hypothesis 2002; 58(3): 237-43. doi: 10.1054/mehy.2001.1499

81. Godlevsky L, Shandra O, Pervak M, Shandra A. Diazepam and electrical stimulation of paleocerebellar cortex inhibits seizures in pentylenetetrazol-kindled rats. Acta Neurobiol Exp 2020; 80(3): doi: 10.21307/ane-2020-028

82. Fisher RS, Velasco AL. Electrical brain stimulation for epilepsy. Nat Rev Neurol 2014; 10(5): 261-70. doi: 10.1038/nrneurol.2014.59

83. Izawa J, Criscimagna-Hemminger SE, Shadmehr R. Cerebellar contributions to reach adaptation and learning sensory consequences of action. $J$. Neurosci 2012; 32 (12): 4230-9. doi: 10.1523/JNEUROSCI.6353-11.2012

84. Baumann O, Borra RJ, Bower JM, Cullen KE, Habas C, Ivry RB, Leggio M, Mattingley JB, Molinari M, Moulton EA et al. Consensus paper: the role of the 
cerebellum in perceptual processes. Cerebellum 2015; 14(2): 197-220. doi:10.1007/s12311-014-0627-7

85. Schmahmann JD. The cerebellum and cognition. Neurosci Lett 2019; 688(1): 26-75. doi: 10.1016/j.neulet.2018.07.005

86. Coenen AM, Van Luijtelaar ELJM. Genetic animal models for absence epilepsy: a review of the WAG/Rij strain of rats. Behav Genet 2003; 33(6): 635-55. doi:10.1023/a:1026179013847

87. Van Luijtelaar G, Van Oijen G. Establishing Drug effects on electrocorticographic activity in a genetic absence epilepsy model: advances and pitfalls. Front Pharmacol 2020; 11:395. doi: 10.3389/fphar.2020.00395

88. Luft AR, Skalej M, Schulz JB, Wete D, Kolb R, Bürk K, Klockgether T, Voigt K. Patterns of age-related shrinkage in cerebellum and brainstem observed in vivo using three-dimensional MRI volumetry. Cereb Cortex 1999; 9(7): 712-21. doi:10.1093/cercor/9.7.712

89. Carney PW, Jackson GD. Insights into the mechanisms of absence seizure generation provided by EEG with functional MRI. Front Neurol 2014; 5: 162. doi: 10.3389/fneur.2014.00162 